\title{
PERSENTASE KEJADIAN KAWIN BERULANG SAPI PERAH YANG TELAH DI IB (INSEMINASI BUATAN) TINGKAT PETERNAK DESA NYAWANG KIDUL DI KUD TANI WILIS KECAMATAN SENDANG KABUPATEN TULUNGAGUNG
}

\section{PERCENTAGE OF REPEAT BREEDER EVIDENCE IN DAIRY COWS AFTER (ARTIFICIAL INSEMINATION) AT FARMER LEVEL OF KUD TANI WILIS IN NYAWANG KIDUL, SENDANG DISTRICT, TULUNGAGUNG CITY.}

\author{
Arda Wahyu Setyadi' ${ }^{1}$, *Pudji Srianto ${ }^{2)}$, Oky Setyo Widodo ${ }^{3)}$, Wurlina $^{4)}$, Abdul Samik ${ }^{5)}$, \\ Tjuk Imam Restiadio \\ ${ }^{1)}$ Student, ${ }^{2,4,5,6}$ Department of Reproduction, ${ }^{3)}$ Department of Animal Husbandry. \\ Faculty of Veterinary Medicine, Universitas Airlangga \\ *Corresponding author: email: pudjisrianto@yahoo.com
}

\begin{abstract}
Dairy cows farm business level of KUD Tani Wilis in Nyawang Kidul, Sendang district, Tulungagung city has some problems resulting low livestock productivity. One of the causes of low levels of dairy reproductivity is the incidence of repeat breeder. Repeat breeder is a condition of a female cow that failed to breed after being mated three or more times with a normal and healthy fertilized bull. The main purpose of this research is to know the risk factor of repeat breeder in dairy cows at farmer level of KUD Tani Wilis in nyawang kidul, Sendang district, Tulungagung city. The type of research is descriptive research. This research was using 32 dairy cows from 6 breeders, the selection of cattles used Simple Random Sampling method. The collection data using questionnaires and direct observations in farms resulted that the evidence rate of dairy cattle's repeat breeder in this research is $45.7 \%$. The results also showed that the influence of knowledge of farmers on disease or reproductive disorders positively correlated with the evidence of repeat breader.
\end{abstract}

Keyword: Percentage, repeat breeder, dairy cattle, reproductivity, a risk of factor.

\section{Pendahuluan}

Sapi perah yang diternakkan di Indonesia umumnya adalah jenis Friesian Holstein, peranakan Friesian Holstein, maupun silangannya. Sapi PFH merupakan sapi kelahiran Indonesia dari induk $\mathrm{FH}$ atausilangannya dengan pejantan atau semen beku FH. Sapi PFH merupakan ternak yang sudah mengalami adaptasi fisiologis, sehingga lebih sesuai dengan daerah tropis dari pada sapi $\mathrm{FH}$ asli. (Akramuzzein, 2009).

Permasalahan reproduksi yang sering terjadi pada sapi perah di Indonesia adalah rendahnya efisiensi reproduksi, pada sapi perah tersebut menandakan ada gangguan reproduksi. Salah satu gejala gangguan reproduksi adanya kejadian kawin berulang (repeat breeder). Kawin berulang adalah suatu keadaan sapi betina yang mengalami kegagalan untuk bunting setelah dikawinkan
3 kali atau lebih dengan pejantan fertil tanpa adanya abnormalitas yang teramati (Amiridis, dkk., 2009).

Rendahnyakeberhasilan perkawinan sapi perah di Indonesia khususnya di Kecamatan Sendang, sudah selayaknya menjadi perhatian karena rendahnya populasi kejadian kawin berulang sangat tinggi dibanding Kecamatan yang lain pada Kabupaten Tulungagung. Yuwananto, 2001).

\section{Materi dan Metode Penelitian}

Materi yang digunakan pada penelitian ini adalah pengambilan data peternak sapi perah Desa Nyawang Kidul di KUD Tani Wilis, Kecamatan Sendang, Kabupaten Tulungagung. Materi penelitian adalah data kegagalan kebuntingan sapi perah setelah tiga kali di IB yang berasal dari hasil sampling tingkat peternak. Penelitian ini mengetahui hubungan faktor-faktor penyebab kejadian 
kawin berulang pada tingkat peternak. Data yang digunakan dalam penelitian ini adalah data primer dan data sekunder.

Data primer diperoleh dan dikumpukan langsung dari peternakan sapi Perah yang berupa hasil identifikasi kejadian kawin berulang di Kecamatan Sendang, Kabupaten Tulungagung, hasil kuesioner dari wawancara dengan peternak, serta pengamatan langsung di peternakan guna mengetahui faktor-faktor risiko penyebab kejadian kawin berulang.

Data sekunder adalah data yang didapatkan dari kejadian dan penyebab kawin berulang sapi perah yang telah di IBtingkat peternak pada KUD Tani Wilis Kecamatan Sendang, Kabupaten Tulungagung.

\section{Analisis Data}

Setelah semua data dikumpulkan, selanjutnya dilakukan pengkodean pada semua poin variabel data kuesioner hal ini dilakukan untuk memudahkan analisis. Data hasil kuesioner dari perhitungan persentase dan faktor risiko kawin berulang pada sapi perah pada tingkat peternak kemudian di olah dalam program data. Hasil tabulasi data jumlah kejadian dan faktor risiko kawin berulang penyebab kawin berulang pada pada sapi perah pada tingkat peternak dianalisis secara deskriptif.

\section{Hasil dan Pembahasan \\ Persentase Kejadian Kawin Berulang Tingkat Peternak \\ Pada sampel persentase kejadian kawin} berulang tingkat peternak yang digunakan dalam penelitian ini adalah 32 ekor sapi betina yang dipelihara oleh 6 peternak di Desa Nyawang Kidul KUD Tani Wilis Kecamatan Sendang Kabupaten Tulungagung. Sapi be- tina yang mengalami kejadian kawin berulang dengan persentase 45,7\% kejadian kawin berulang. Data hasil persentase kejadian kawin berulang tingkat peternak dapat dilihat pada tabel 1.

Pada persentase kejadian kawin berulang sapi perah yang telah di IB tinggat peternak di Desa Nyawang Kidul KUD Tani Wilis Kecamatan Sendang, Kabupaten Tulungagung. Sapi Betina di Desa Nyawang Kidul dengan total 32 ekor yang positif mengalami kejadian kawin berulang sebanyak 7 ekor dengan persentase $45,7 \%$ kejadian kawin berulang.

\section{Pengaruh Hubungan antara Faktor Resiko Kejadian Kawin Berulang.}

Pada hasil penelitian ini pengaruh dan hubungan faktor resiko kejadian kawain berulang pada Desa Nyawang Kidul di KUD Tani Wilis Kecamatan Sendang Kabupaten Tulungagung dengan menggunakan 32 ekor sapi perah yang dipelihara dari 6 peternak. Pada faktor penilaian tiap variabel karakteristik peternak, pengetahuan peternak tentang siklus estrus, pengetahuan peternak tentang reproduksi ternak, faktor perkandangan, pakan dan air minum, dan pelaksanaan inseminasi buatan menunjukkan bahwa analisis hubungan antara persentase dan faktor risiko kejadian kawin berulang pada sapi perah pada tingkat peternak tidak ada pengaruh yang dihasilkan. Data hasil kuesioner pengaruh hubungan faktor resiko kejadian kawin berulang sapi perah Desa Nyawang Kidul di KUD Tani Wilis, Kecamatan Sendang, Kabupaten Tulungagung dapat dilihat pada tabel 2 .

Tabel 1. Persentase Kejadian Kawin Berulang Sapi Perah yang Telah di IB Tingkat Peternak Desa Nyawang Kidul KUD Tani Wilis Kecamatan Sendang, Kabupaten Tulungagung.

\begin{tabular}{cccccc}
\hline NO & Desa & Jumlah Ternak & \multicolumn{2}{c}{ Jumlah Sampel } & Hasil \\
& & & Positif & Negatif & Deskriptif \\
\hline $\mathbf{1}$ & Nyawang Kidul & 18 & 2 & 0 & $9 \%$ \\
$\mathbf{2}$ & Nyawang Kidul & 3 & 0 & 0 & $0 \%$ \\
$\mathbf{3}$ & Nyawang Kidul & 4 & 0 & 0 & $0 \%$ \\
$\mathbf{4}$ & Nyawang Kidul & 4 & 5 & 0 & $8 \%$ \\
$\mathbf{5}$ & Nyawang Kidul & 2 & 0 & 0 & $0 \%$ \\
$\mathbf{6}$ & Nyawang Kidul & 1 & 0 & 0 & $0 \%$ \\
\hline & Total & 32 & 7 & 0 & $45,7 \%$ \\
\hline
\end{tabular}


Tabel 2. Pengaruh Hubungan antara Faktor Resiko Kejadian Kawin Berulang Sapi Perah Desa Nyawang Kidul di KUD Tani Wilis, Kabupaten Sendang, Kabupaten Tulungagung.

\begin{tabular}{|c|c|c|c|c|}
\hline \multirow{2}{*}{ NO } & \multirow{2}{*}{ Veriabel } & \multirow{2}{*}{ Keterangan } & \multicolumn{2}{|c|}{ Kejadian Kawin Berulang } \\
\hline & & & Positif & Negatif \\
\hline & \multicolumn{4}{|c|}{ 1. Karakteristik Peternak } \\
\hline \multirow[t]{9}{*}{1.1} & \multicolumn{4}{|c|}{ Pendidikan Terakhir } \\
\hline & SD & Tamat SD & 2 & 2 \\
\hline & $19,0 \%$ & Tdk Tamat SD & 7 & 10 \\
\hline & SMP & Tamat SMP & 2 & 5 \\
\hline & $33.3 \%$ & Tdk Tamat SMP & 8 & 6 \\
\hline & SMA & Tamat SMA & 5 & 4 \\
\hline & $42,9 \%$ & Tdk Tamat SMA & 5 & 7 \\
\hline & PT & PT & 0 & 1 \\
\hline & $4,8 \%$ & Bukan PT & 9 & 11 \\
\hline \multirow[t]{2}{*}{1.2} & Pengalaman beternak sapi: & $<5$ Tahun $(9,5 \%)$ & 0 & 1 \\
\hline & & $>5$ Tahun $(90,5 \%)$ & 10 & 10 \\
\hline \multicolumn{5}{|c|}{ 2. Pengetahuan peternak Tentang Reproduksi Ternak } \\
\hline \multirow[t]{2}{*}{2.1} & $\begin{array}{c}\text { Mengetahui penyakit } \\
\text { (ganggun) reproduksi ternak }\end{array}$ & Ya $(42,9 \%)$ & 0 & 9 \\
\hline & $\begin{array}{l}\text { yang berpengaruh terhadap } \\
\text { kebuntingan ternak sapi: }\end{array}$ & Tidak $(57,1 \%)$ & 10 & 2 \\
\hline \multirow[t]{3}{*}{2.2} & $\begin{array}{l}\text { Mengetahui ciri-ciri sapi } \\
\text { perah ketika mengalami }\end{array}$ & Ya $(42,9 \%)$ & 0 & 9 \\
\hline & $\begin{array}{l}\text { kelainan reproduksi atau } \\
\text { gangguan penyakit } \\
\text { reproduksi }\end{array}$ & Tidak $57,1 \%$ & 10 & 2 \\
\hline & \multicolumn{4}{|c|}{ 3. Perkandangan } \\
\hline \multirow[t]{2}{*}{3.1} & \multirow{2}{*}{$\begin{array}{l}\text { Terdapat Selokan saluran } \\
\text { pembuangan kotoran dan air } \\
\text { kencing: }\end{array}$} & $\mathrm{Ya}(95,2 \%)$ & 9 & 11 \\
\hline & & Tidak $(4,8 \%)$ & 1 & 0 \\
\hline \multirow[t]{2}{*}{3.2} & \multirow{2}{*}{$\begin{array}{c}\text { Alas kandang sering di } \\
\text { bersihkan: }\end{array}$} & Ya $(95,2 \%)$ & 9 & 11 \\
\hline & & Tidak $(4,8 \%)$ & 1 & 0 \\
\hline \multirow[t]{2}{*}{3.3} & \multirow{2}{*}{$\begin{array}{l}\text { Saluran pembungan } \\
\text { bermuara suatu tempat: }\end{array}$} & Ya $(95,2 \%)$ & 9 & 11 \\
\hline & & Tidak $(4,8 \%)$ & 1 & 0 \\
\hline \multicolumn{5}{|c|}{ 4. Pakan dan Air Minum } \\
\hline \multirow[t]{2}{*}{4.1} & \multirow{2}{*}{$\begin{array}{l}\text { Pemberian pakan dalam } \\
\text { sehari: }\end{array}$} & 3 kali $(66,7 \%)$ & 5 & 2 \\
\hline & & $>3$ kali $(33,3 \%)$ & 5 & 9 \\
\hline \multirow[t]{2}{*}{4.2} & \multirow{2}{*}{$\begin{array}{l}\text { Pemberian pakan untuk sapi } \\
\text { perah diberikan pada waktu } \\
\text { pagi, siang, dan sore: }\end{array}$} & Ya $(66,7 \%)$ & 5 & 2 \\
\hline & & Tidak $(33,3 \%)$ & 5 & 9 \\
\hline & \multicolumn{4}{|c|}{ 5. Pelaksanaan Inseminasi Buatan (IB) } \\
\hline \multirow[t]{2}{*}{5.1} & Kualitas semen yang & Baik $(95,2 \%)$ & 0 & 11 \\
\hline & digunakan untuk IB: & Buruk $(4,8 \%)$ & 1 & 9 \\
\hline \multirow[t]{2}{*}{5.2} & Keterampilan inseminator & Baik $(95,2 \%)$ & 0 & 11 \\
\hline & saat melakukan IB: & Buruk $(4,8 \%)$ & 1 & 9 \\
\hline \multirow[t]{2}{*}{5.3} & Kesulitan untuk Inseminator & Sulit $(9,5 \%)$ & 2 & 2 \\
\hline & $\begin{array}{l}\text { saat ternak sapi perah ingin } \\
\text { di IB: }\end{array}$ & Tdk Sulit $(90,5 \%)$ & 10 & 9 \\
\hline
\end{tabular}


Secara umum, pendidikan terakhir para peternak sapi perah pada Desa Nyawang Kidul di KUD Tani Wilis, Kecamatan Sendang, Kabupaten Tulungagung di dominasi oleh SMA sebesar 42,9\%, SMP 33,3\%, di tingkat SD $19 \%$ dan 4,8\%. Pengalaman beternak sapi selama $\geq 5$ tahun sebesar $90,5 \%$, sedangkan pengalaman beternak sapi perah $<5$ tahun sebesar $9,5 \%$.

Pengetahuan peternak tentang reproduksi dengan cara mengetahui penyakit reproduksi ternak berpengaruh terhadap kebuntingan sapi dan mengetahui ciri-ciri sapi perah ketika mengalami kelainan reproduksi atau gangguan penyakit reproduksi dari berapa peternak menjawab persentase Ya 42,9\% dan Tidak $57,1 \%$.

Perkandangan peternak terdapat selokan saluran pembuangan kotoran dan air kencing, alas kandang sering di bersihkan dan saluran pembuangan bermuara satu tempat dari berapa peternak menjawab persentase Ya 95,2\% dan Tidak 4,8\%.

Pakan dan air minum pemberian pakan dalam sehari 3 kali $66,7 \%$ sedangkan kurang $>3$ kali 33,3\%. Pada pemberian pakan untuk sapi perah diberikan $3 x$ pada waktu pagi, siang dan sore dari peternak menjawab persentase Ya 66,7\% dan Tidak 33,3\%.

Pelaksanaan inseminasi buatan (IB) pada kualitas semen yang digunakan untuk IB, keterangan inseminator saat IB dari peternak menjawab persentase Baik 95,2\% Buruk 4,8\% dan kesulitan untuk inseminator saat ternak sapi perah ingin di IB dari peternak menjawab persentase Sulit 9,5\% Tidak sulit 90,5\%.

\section{Faktor Perkandangan}

Faktor perkandangan $100 \%$ terdiri dari : terdapat tempat pakan dan air minum dalam kandang $100 \%$, tersedia tempat penampungan kotoran sapi atau sisa sisa pakan pada kandang $100 \%$, terdapat genangan air atau kotoran di sekitar kandang sapi perah $100 \%$, terdapat selokan saluran pembuangan kotoran dan air kencing 95,2\%, pembersihan kandang tidak dengan desinfektan atau deterjen $100 \%$, alas kandang sering di bersihkan 95,2\%, saluran pembuangan anda bermuara suatu tempat $95,2 \%$, dalam kandang tidak di temukan jenis hewan lain 76,2\%.

Kandang sebagai tempat pemeliharaan sapi perah mestinya memiliki konstruksi yang kuat; drainase dan saluran pembuangan limbah baik; tempat kering dan tidak tergenang air; lantai dengan kemiringan 2-5 derajat, tidak licin, tidak kasar, mudah kering dan tahan injakan serta menggunakan alas (karpet/matras); dan luas kandang sesuai peruntukannya (Direktorat Perbibitan Ternak, 2014). Kandang sapi perah dapat dilihat pada gambar 1.

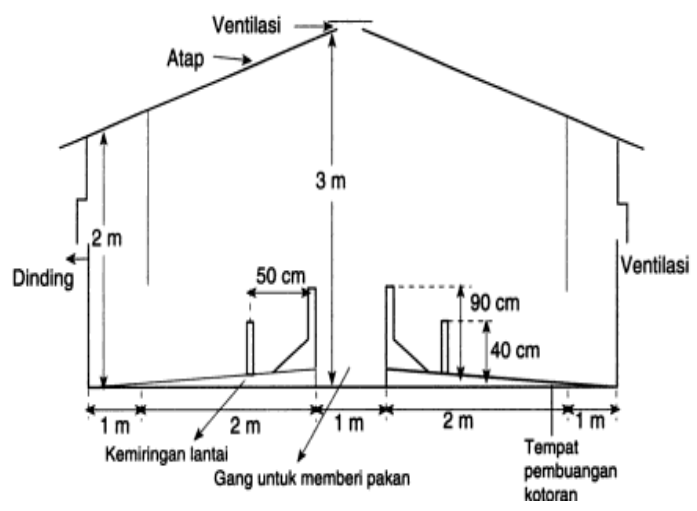

Gambar 1. Skema Kandang Sapi Perah Bentuk Ganda (Leonardus, 2008).

\section{Kesimpulan}

Berdasarkan hasil penelitian prevalensi dan faktor resiko kejadian kawin berulang pada sapi perah pada tingkat peternak di KUD Tani Wilis Kecamatan Sendang, Kabupaten Tulungagung dapat disimpulkan bahwa:

1. Prevalensi kejadian kawin berulang pada sapi perah pada tingkat peternak di KUD Tani Wilis, Kecamatan Sendang, Kabupaten Tulungagung se-besar 47,6\% dari kejadian kawin berulang.

2. Pengaruh pengetahuan peternak terhadap penyakit pada sapi perah atau gangguan reproduksi pada sapi perah berkorelasi positif terhadap kejadian kawin berulang.

\section{Daftar Pustaka}

Akramuzzein. 2009. Program Evaluasi Pemberian Pakan Sapi Perah Untuk Tingkat Peternak dan Koperasi Menggunakan Microsoft Acces. Skripsi. Bogor: Institut Pertanian Bogor.

Amiridis, GS., Tsiligianni Th, Dovolou E, Rekkas C, Vouzaras D, Menegatosi. 2009. Combined Administration Of Gonadotropin-Releasing Hormone, Progesterone, And Meloxicam Is An Effective Treatment For The RepeatBreeder Cow. Theriogenology 72: 542548. 
Arda Wahyu Setyadi, dkk.

Direktorat Perbibitan Ternak. 2014. Pedoman Pembibitan Sapi Perah Yang Baik. Direktorat Jenderal Peternakan Dan Kesehatan Hewan Kementerian Pertanian.

Leonardus Nababan, Randy. 2008. Kegiatan Usaha Pemeliharaan Sapi Perah di PT. Taurus Dairy Farm Kecamatan Cicurug
Kabupaten Sukabumi. Universitas Jenderal Soedirman: Purwokerto

Yuwananto. 2001. Pengelolaan dan Efisiensi Reproduksi pada Sapi Perah di KUD Dadi Jaya Kecamatan Purwodadi Kabupaten Pasuruan Jawa Timur [Skripsi]. Fakultas Kedokteran Hewan. Universitas Airlangga. Surabaya. 